Article

\title{
Study of Atmospheric Carbon Dioxide Retrieval Method Based on Normalized Sensitivity
}

\author{
Liang Zhao ${ }^{1,2}$, Shengbo Chen ${ }^{2}$, Yong Xue ${ }^{1, * \mathbb{C}}$ and Tengfei Cui ${ }^{1}$ \\ 1 School of Environment and Spatial Informatics, China University of Mining and Technology, \\ Xuzhou 221116, China; liangzhao@cumt.edu.cn (L.Z.); tengfeicui@cumt.edu.cn (T.C.) \\ 2 College of Geoexploration Science and Technology, Jilin University, Changchun 130026, China; \\ chensb@jlu.edu.cn \\ * Correspondence: yxue@cumt.edu.cn
}

Citation: Zhao, L.; Chen, S.; Xue, Y.; Cui, T. Study of Atmospheric Carbon Dioxide Retrieval Method Based on Normalized Sensitivity. Remote Sens. 2022, 14, 1106. https://doi.org/ $10.3390 /$ rs 14051106

Academic Editor: Dimitrios Balis

Received: 7 January 2022

Accepted: 11 February 2022

Published: 24 February 2022

Publisher's Note: MDPI stays neutral with regard to jurisdictional claims in published maps and institutional affiliations.

Copyright: (C) 2022 by the authors. Licensee MDPI, Basel, Switzerland. This article is an open access article distributed under the terms and conditions of the Creative Commons Attribution (CC BY) license (https:// creativecommons.org/licenses/by/ $4.0 /)$.

\begin{abstract}
The satellite-based remote-sensing detection of $\mathrm{CO}_{2}$ can provide long-term and continuous observations at the global scale, and is the primary observational approach to monitoring $\mathrm{CO}_{2}$ changes. Surface albedo and aerosol are two significant challenges for retrieving $\mathrm{CO}_{2}$ concentrations from near-infrared remote-sensing data. This research addressed the dependence of radiance sensitivities on $\mathrm{CO}_{2}$ concentration, aerosol, surface albedo, and water vapor. The band ratio method was used to retrieve $\mathrm{CO}_{2}$ with band selection of the high- and low-sensitivity channels to restrain the influence of surface albedo and aerosol. Results showed that the band ratio method had better efficiency at reducing the impact of aerosol and surface albedo than that of the optical estimation method. The retrieval error of aerosol was reduced by $2.5 \%$ overall. We validated the band ratio method retrieval results with two TCCON sites and the GOSAT L3 product. Pearson's correlation coefficient, mean bias, mean absolute bias, and root mean squared error of the monthly retrieval data of the band ratio method showed high agreement between the TCCON in Park Falls and Wollongong. These results indicate that the band ratio method based on normalized sensitivity can effectively reduce the influence of surface albedo and aerosol.
\end{abstract}

Keywords: carbon dioxide; SCIATRAN; normalized sensitivity; albedo; aerosol; GOSAT

\section{Introduction}

The satellite-based remote-sensing detection of greenhouse gases can provide longterm and continuous observations at the global scale to better understand the spatial and temporal patterns of sources and sinks of $\mathrm{CO}_{2}$ [1]. The main near-infrared satellite instruments include Scanning Imaging Absorption spectroMeter for Atmospheric CHartographY (SCIAMACHY) [2], Greenhouse gases Observing SATellite (GOSAT) [3], Orbiting Carbon Observatory-2 (OCO-2) [4], and TanSat (CarbonSat, Tan means "carbon" in Chinese) [5]. SCIAMACHY worked from March 2002 to April 2012 and passively observed backscattered radiation reflected, transmitted, or emitted by Earth's atmosphere and surface in the wavelength ranging between 240 and $2380 \mathrm{~nm}$ [2]. GOSAT, launched in 2009, observes backscattered sunlight with a spectral resolution of $0.2 \mathrm{~cm}^{-1}$ [6]. The OCO-2 satellite was successfully launched in July 2014. The design of detecting accuracy of the OCO-2 is $1-2$ ppmv (0.3-0.5\%) [7]. The TanSat satellite is equipped with an ultrahigh spectral grating carbon dioxide spectrometer and a cloud and aerosol polarimetry imager [5].

In the near-infrared region, the most significant retrieval errors of atmospheric $\mathrm{CO}_{2}$ are caused by cirrus clouds, aerosols, and surface albedo. Even under clear sky conditions, the aerosol scattering effect is crucial for suppressing the near-infrared band [8]. The scattering effects of aerosols can change the photon path and result in the wrong estimation of $\mathrm{CO}_{2}$ in the atmosphere. Global $\mathrm{CO}_{2}$ source and sink distribution studies require that the retrieval accuracy of $\mathrm{CO}_{2}$ is less than $0.2 \%$ [9]. Therefore, the quantitative analysis of the spatial and temporal variation of global $\mathrm{CO}_{2}$ sources and sinks puts forward high requirements for 
the accuracy of atmospheric $\mathrm{CO}_{2}$ measurements $[10,11]$. The surface feature parameter is the main input parameter in the atmospheric radiation transfer model. The accuracy of surface albedo is a significant factor in retrieving the measurements of global greenhouse gas $\mathrm{CO}_{2}$. Existing global products of surface albedo were Moderate-resolution Imaging Spectroradiometer (MODIS) MODIS Combined Data 43 (MCD43) products, and the accuracy of bidirectional reflectance distribution function (BRDF) products are generally around $10 \%$ [12].

Atmospheric $\mathrm{CO}_{2}$ algorithms are mainly divided into two types: differential absorption spectroscopy (DOAS) [13] and optical estimation method (OEM) [14]. The DOAS method is mainly used for SCIAMACHY, such as weighting function modified- differential optical absorption spectroscopy (WFM-DOAS) [13], iterative maximum a posteriori differential optical absorption spectroscopy (IMAP-DOAS) [15], and full spectral initiation weighting function modified differential optical absorption spectroscopy (FSI/WFMDOAS) [16]. For OCO-2 and GOSAT, researchers often adopt the OEM [17-19] and photon path length probability density function (PPDF) algorithms [20]. As a common $\mathrm{CO}_{2}$ retrieval method in the near-infrared band, the OEM is a physical retrieval method based on the radiation transfer model using a cost function to gradually approximate the real value of $\mathrm{CO}_{2}$ in iteration [14]. For GOSAT and OCO-2 data, various retrieval algorithms have been developed to account for scattering by particles. In version v01.xx of their Level 2 algorithm, the Japanese National Institute for Environmental Studies (NIES) team assumed a uniform distribution of aerosols in a $2 \mathrm{~km}$ thick layer from the ground. It retrieves only aerosol optical thickness [21]. The National Aeronautics and Space Administration (NASA) Atmospheric $\mathrm{CO}_{2}$ Observations from Space (ACOS) team retrieves the extinction profiles of two aerosol types and two cloud types (one water cloud and one cirrus cloud), and considers 20 vertical levels [17]. The University of Leicester Full Physics (UoL-FP) algorithm retrieves the extinction profiles of one cirrus and two aerosol types on 20 levels [18]. A full physics retrieval algorithm called remote sensing of greenhouse gases for carbon cycle modeling) retrieves $\mathrm{XCO}_{2}$ (dry-air mixing ratio of $\mathrm{CO}_{2}$ ) and $\mathrm{XCH}_{4}$ (dry-air mixing ratio of $\mathrm{CH}_{4}$ (RemoTeC) and three effective aerosol parameters representing particle amount, size, and height distributions [19]. The UoL-FP algorithm was implemented for TanSat nadir mode $\mathrm{XCO}_{2}$ retrieval [22].

The OEM for GOSAT data uses aerosol lookup tables with four different proportions of the combination of known aerosol types to remove the impact of aerosol [23]. The $\mathrm{CO}_{2}$ concentration retrieval results using GOSAT data were close to official product accuracy and were less than $1 \%$ with ground observation retrieval results under the condition of atmospheric aerosol optical thickness less than 0.3 [24]. However, the effective retrieval of $\mathrm{CO}_{2}$ concentration under a high aerosol background condition needs to be improved. These methods filter observational data, and remove poor quality and cloudy data. Then, they are combined with a lookup table of the absorption coefficient and auxiliary aerosol data to deal with the scattering effect caused by the light path. However, this preprocessing probably removes valuable observational data and increases the retrieval error caused by overestimating the influence of aerosol, which may underestimate $\mathrm{CO}_{2}$ concentration in a high albedo surface area [11].

The limitation of the OEM is the cost function, which is affected by the observed values and restricted by the accuracy of the prior knowledge. Deviation in prior knowledge leads to the final retrieval result changing. Therefore, there may be seasonal and regional influences on the selection of prior knowledge. These methods do not address the effect of surface albedo and use all the channels to retrieve the process. Moreover, using all the channels to retrieve $\mathrm{CO}_{2}$ is redundant regarding operational cost.

This work aims to improve the band ratio method (BRM) atmospheric $\mathrm{CO}_{2}$ retrieval method, considering various factors affecting the accuracy of atmospheric $\mathrm{CO}_{2}$ retrieval and the limitations of existing retrieval methods. In Section 2, the atmospheric radiative transfer model is used to simulate the influence of factors. In Section 3, the normalized sensitivities of the influence factors are analyzed to select the retrieval channel. High-normalized 
sensitivity channels and low-normalized sensitivity channels are chosen to improve the existing retrieval algorithm and establish a more accurate GOSAT data retrieval method in Section 4. The validation is also shown in Section 4. The discussion and conclusions of the study are presented in Sections 4 and 5.

\section{Data and Methods}

2.1. Data

\subsubsection{GOSAT Data}

The Thermal and Near-infrared Sensor for carbon Observation (TANSO) aboard the GOSAT, launched on 23 January 2009 in Japan is the first instrument dedicated to recording $\mathrm{CO}_{2}$ and $\mathrm{CH}_{4}$ concentrations, designed by Japan Aerospace Exploration Agency (JAXA) [3] The TANSO is a nadir-looking Fourier transform spectrometer (FTS) with four spectral bands, from the visible to the thermal infrared $(0.76-15 \mathrm{~mm})$, and it can measure $\mathrm{XCO}_{2}$ and $\mathrm{XCH}_{4}$ from SWIR bands with global coverage every three days.

GOSAT products can be divided into the following levels: L0, FTS-L1A, FTS- Short Wavelength InfraRed (SWIR) L1B, FTS-Thermal Infrared (TIR) L1B, Cloud and Aerosol Imager (CAI) L1B products, FTS-SWIR L2 products, CAI L2 products, FTS-SWIR L3 products, CAI L3 products. FTS L1B data are radiance spectra. CAI 1B data are pixel-by-pixel radiance. FTS L2, CAI L2, FTS L3, CAI L3, L4A, and L4 B data products are retrieved from physical quantities such as the atmospheric concentrations of $\mathrm{CO}_{2}$ and $\mathrm{CH}_{4}$ [3].

This study uses the GOSAT FTS SWIR L2 data for retrieval. FTS L3 monthly products are used to validate the retrieval results.

\subsubsection{TCCON}

Total Carbon Column Observing Network (TCCON) is a network of ground-based solar Fourier transform spectrometers operating in the near-infrared spectral region to validate and calibrate the $\mathrm{XCO}_{2}$ data from satellite measurement products [25]. Data products are total columns of $\mathrm{CO}_{2}, \mathrm{CH}_{4}, \mathrm{HDO}, \mathrm{CO}$, and $\mathrm{N}_{2} \mathrm{O}$ with uncertainty lower than $0.25 \%$ [11]. TCCON data products from the Park Falls and Wollongong sites were used to validate the retrieval results in this study [26,27] (Figure 1).

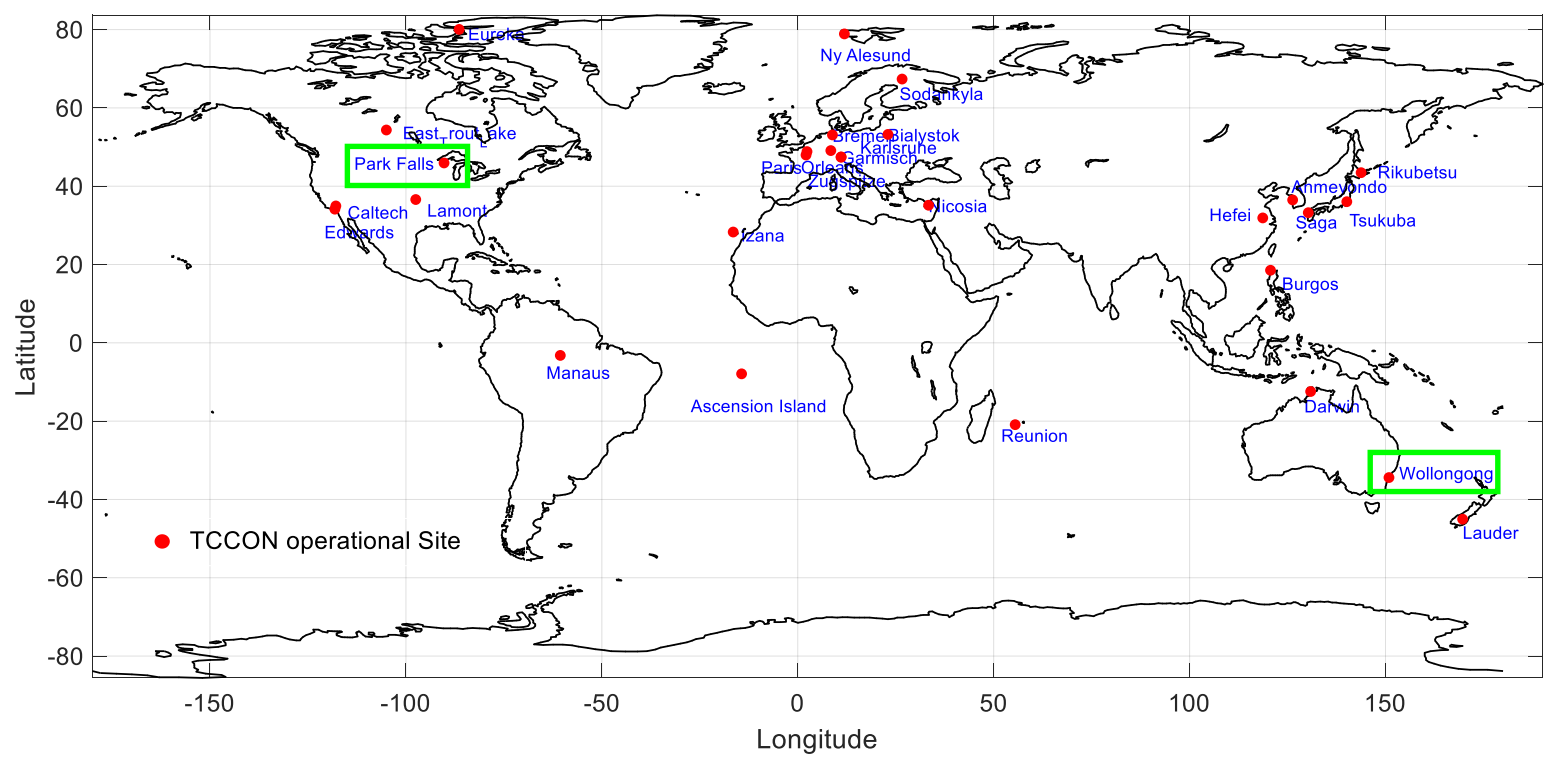

Figure 1. Global distribution of TCCON sites (Park Falls and Wollongong are marked in green) (https:/ / tccondata.org/ accessed on 6 January 2022).

Park Falls is surrounded by forest in the United States. This site has relatively uniform surface properties and is reasonably far from anthropogenic $\mathrm{CO}_{2}$ sources. As the observational data for calibration of greenhouse gases, flight-based validation was conducted in 
Park Falls a few times to ensure the accuracy of the observational data [4]. This site was selected to represent a simple retrieval scenario of surface and aerosol conditions. The Wollongong site in Australia is located on the eastern coast of New South Wales, south of Sydney, between the ocean and a sharp escarpment. Wollongong was one of the most challenging sites for identifying the tendency of optical path modification, which could be related to the rough surface topography in Wollongong's vicinity [28]. This site was selected to represent the complex retrieval scenario of surface and aerosol conditions.

\subsection{Methods}

\subsubsection{SCIATRAN Model}

The Scanning Imaging Absorption spectrometer for Atmospheric cartography radiative transfer model (SCIATRAN) is based on the well-known Global Ozone Monitoring Experiment (GOMETRAN) model, which was initially developed to simulate solar radiation backscattered from the atmosphere and reflected from Earth's surface [29]. The SCIATRAN is mainly concerning molecular line absorption and considers multiple scattering. The SCIATRAN solves the radiative transfer equation for pseudo-spherical geometry and is valid for nadir up to a solar zenith angle of about 92 degrees. After decades of development, the SCIATRAN model was updated to SCIATRAN 3.7.5. The spectral range was from $175.44 \mathrm{~nm}$ to $40 \mu \mathrm{m}$, including $\mathrm{O}_{3}, \mathrm{~N}_{2}, \mathrm{ClO}, \mathrm{OClO}, \mathrm{BrO}, \mathrm{HCHO}, \mathrm{NO}_{3}, \mathrm{O}_{4}, \mathrm{O}_{2}, \mathrm{H}_{2} \mathrm{O}$, $\mathrm{CO}_{2}, \mathrm{CO}, \mathrm{CH}_{4}, \mathrm{~N}_{2} \mathrm{O}, \mathrm{NO}, \mathrm{NH}_{3}, \mathrm{HNO}_{3}, \mathrm{OH}, \mathrm{HF}, \mathrm{HCL}, \mathrm{HBR}, \mathrm{HI}, \mathrm{Na}, \mathrm{Mg}, \mathrm{Mg}+$, Rayleigh scattering, aerosols, and clouds [30].

\subsubsection{Normalized Analysis Method}

The main parameters influencing the atmospheric radiation transfer model are $\mathrm{CO}_{2}$ concentration, aerosol, surface albedo, and water vapor. Therefore, it is necessary to analyze the impact of these parameters using the atmospheric radiative transfer model.

With other parameters remaining unchanged, the output results of the model change along with the change of the initial values of a particular setting. The larger change of model output value indicates the higher sensitivity of the parameter. The degree of sensitivity is expressed by the rate of change of radiance, which is defined as follows:

$$
S=\frac{r_{1}-r_{0}}{r_{0}} \times 100 \%
$$

where $S$ is the rate of radiance, $r_{0}$ is the simulated radiation value under the initial background value, $r_{1}$ is the simulated radiation value after changing the parameter. The radiance rate is the absolute rate of radiance. In this study, the absolute radiance rates are normalized to the range of 0 to 1 using min-max normalization, which represents the normalized sensitivity of relative radiance change between different bands. Min-max normalization is defined as follows:

$$
x^{\prime}=\frac{x-\min (x)}{\max (x)-\min (x)}
$$

where $x$ is an original value, $x^{\prime}$ is the normalized value. $\operatorname{Min}(x)$ is the minimal normalized value. $\operatorname{Max}(x)$ is the maximal normalized value. The lowest normalized sensitivity across all the bands locates the most intense absorption peak. The higher normalized sensitivity of the band indicates the absorption peak of this band is shallower than other bands.

Light-path lengthening or shortening depends on cloud and cirrus coverage, aerosol type, height and load, and surface albedo [31]. Aerosol scattering in the atmosphere could change the photon path distribution, which is often considered to be the main source of error in the remote sensing of greenhouse gases [32]. The high surface albedo usually has the most significant effect on the reflected radiance observed at the top of the atmosphere, even in the presence of aerosol scattering [33]. In a clear sky, aerosol and surface albedo are the two parameters that affect the absolute radiance rate more than other parameters do. Our method to reduce the aerosol and surface albedo effect is to look for a consistent band with normalized sensitivity. Taking surface albedo as an example, if the normalized 
sensitivities of surface albedo in two bands are the same, the effects of surface albedo can be eliminated by the ratio of two bands.

This study uses the SCIATRAN radiative transfer model to conduct sensitivity analysis on the parameters affecting $\mathrm{CO}_{2}$ in the near-infrared band, including initial $\mathrm{CO}_{2}$ concentration, aerosol, surface albedo, and water vapor.

\subsubsection{Band Ratio Method (BRM)}

Two channels with coincident normalized sensitivities were selected to minimize the surface albedo error and aerosol scattering effect in the retrieval process. These two channels should have different sensitivity levels for $\mathrm{CO}_{2}$ concentration. The BRM is applied to counteract the surface albedo and aerosol scattering influence.

In the 1565-1590 nm band, solar radiation is weakened by the absorption of $\mathrm{CO}_{2}$ and water vapor and aerosol scattering through the atmosphere. Lastly, radiance $I$ of satellite observations can be expressed as follows:

$$
I=\gamma I_{0} \cdot e^{-\tau / \mu}
$$

where $I_{0}$ is the solar radiation at the top of the atmosphere, $\mu$ is the cosine of the zenith angle, and $\tau$ is the vertical optical thickness of the atmosphere. $\gamma$ is surface albedo. Rayleigh scattering varies gradually with wavelength and can be regarded as constant in a narrow range. Then, the atmospheric optical thickness can be expanded as follows:

$$
I=\gamma I_{0} \cdot e^{-\left(\tau_{\mathrm{CO}_{2}}+\tau_{\mathrm{H}_{2} \mathrm{O}}+\tau_{\mathrm{aer}}\right) / \mu}
$$

where $\tau_{\mathrm{CO}_{2}}, \tau_{\mathrm{H}_{2} \mathrm{O}}$, and $\tau_{\text {aer }}$ are the optical thickness of $\mathrm{CO}_{2}$ gas absorption, water vapor absorption, and aerosol extinction, respectively. In BRM, the equation can be expressed as follows:

$$
\frac{I_{\lambda_{1}}}{I_{\lambda_{2}}}=\frac{I_{0, \lambda_{1}}}{I_{0, \lambda_{2}}} \cdot e^{-\left(\left(\tau_{\mathrm{CO}_{2}, \lambda 1}-\tau_{\mathrm{CO}_{2}, \lambda 2}\right)+\left(\tau_{\mathrm{H}_{2} \mathrm{O}, \lambda 1}-\tau_{\mathrm{H}_{2} \mathrm{O}, \lambda 2}\right)+\left(\tau_{a \sigma, \lambda 1}-\tau_{\alpha r, \lambda 2}\right)\right) / \mu}
$$

The BRM can restrain the effects of surface albedo and aerosol on the two bands where the surface albedo and aerosol influence are consistent. Therefore, ratio $Y$ replaces absolute radiance $y$ to reduce the uncertainty of surface albedo and aerosol.

$$
Y=\frac{I_{\lambda_{1}}}{I_{\lambda_{2}}}
$$

where $\lambda_{1}$ is the high sensitivity band of $\mathrm{CO}_{2}$ concentration, and $\lambda_{2}$ is the low sensitivity band of $\mathrm{CO}_{2}$ concentration. The normalized sensitivity of the aerosol and surface albedo in two bands $\lambda_{1}$ and $\lambda_{2}$ are consistent. The Gauss-Newton iterative method is described as follows:

$$
x_{i+1}=x_{i}+\hat{S}\left[K_{i}^{T}\left(Y-F\left(x_{i}, b\right)\right)-S_{a}^{-1}\left(x_{i}-x_{a}\right)\right]
$$

where $S_{\alpha}$ is the covariance error matrix of initial estimation. $F\left(x_{i}\right)$ is the forward model to estimate the value of $x_{i} . K_{i}$ is the Jacobi matrix (weight function) of $x_{i}$.K depends on the state of $x$. Therefore, the Gauss-Newton iteration is used to obtain the model's optimal solution, which is $\hat{x} . \hat{S}$ is the posterior error matrix: $\hat{S}=\left(K^{T} S_{\varepsilon}^{-1} K+S_{\alpha}^{-1}\right)^{-1}$. The iterative process is stopped when the relative change of the retrieved parameter is $<0.2 \%$ or the retrieved parameter does not reach unrealistic values during the iteration.

\subsubsection{Validation Method}

The preprocess of satellite data retrieval includes downloading and reading GOSAT data, removing cloud-affected observation data, setting the parameter of atmospheric prior profile data, sea level height, surface albedo, and other ancillary data. 
The effect of clouds is the main source of greenhouse-gas retrieval errors. The influence of the cloud is not considered in the existing algorithms. Therefore, when using GOSAT data for $\mathrm{XCO}_{2}$ inversion, cloud pixels must be excluded in the field of view. GOSAT-FTS observation data under clear sky conditions are selected for retrieval using GOSAT'S CAI cloud product data. Atmospheric temperature, humidity, pressure, and water vapor profiles are from the database that comes with SCIATRAN. The surface albedo is from the MODIS MCD43C3 $\left(0.05^{\circ}\right.$ grid) product. The solar spectrum is the Kurucz solar spectrum with a wavenumber interval of $0.01 \mathrm{~cm}^{-1}$ (http: / / kurucz.harvard.edu, accessed on 6 January 2022). The surface albedo is set to the Lambert body, which does not change with the wavelength due to the narrow range of the selected band. Observed data were selected under clear sky conditions. The solar zenith angle of the observed data was less than $60^{\circ}$, and the nadir angle was less than $30^{\circ}$. The retrieval results of GOSAT were lastly compared with the TCCON ground-based retrieval results.

Therefore, GOSAT-FTS satellite data and TCCON data on the same day were selected to achieve a sufficient number of days of data. The retrieval process of $\mathrm{CO}_{2}$ was to compare the ratio of GOSAT satellite observation of the spectrum simulated by the SCIATRAN model.

The daily retrieval data of TCCON and the daily retrieval results from the BRM used in this paper were compared. The monthly retrieval data of TCCON, GOSAT L3 monthly results were used to compare with the monthly retrieval results by the BRM. Two sites of TCCON retrieval data are used for verification: Park Falls and Wollongong (Figure 9). The time range was from April to September 2011.

Satellite retrieval results (BRM or GOSAT L3) and TCCON were evaluated by mean bias (MB), mean absolute bias (MAB), root mean squared error (RMSE), and Pearson's correlation coefficient (CORR), defined as:

$$
\begin{aligned}
& \mathrm{MB}=\frac{1}{T} \sum_{t=1}^{T}\left(\mathrm{XCO}_{2 \_ \text {Satellite }}-\mathrm{XCO}_{2 \_} \text {TCCON }\right) \\
& \mathrm{MAB}=\frac{1}{T} \sum_{t=1}^{T} \mid X \mathrm{CO}_{2} \_ \text {Satellite }-X \mathrm{XO}_{2} \_T C C O N \mid \\
& \mathrm{RMSE}=\sqrt{\frac{1}{T} \sum_{t=1}^{T}\left(\mathrm{XCO}_{2} \text { Satellite }_{2}-\mathrm{XCO}_{2} \_ \text {TCCON }\right)^{2}}
\end{aligned}
$$

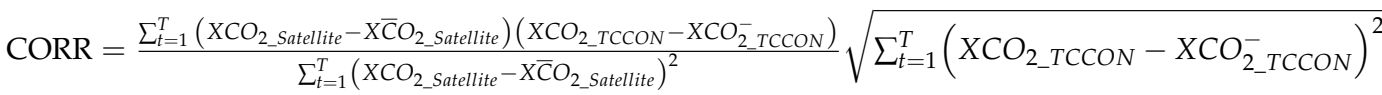

where $\mathrm{XCO}_{2}$ TCCON is the TCCON XCO 2 results, $T$ is the total number of the observations, $\mathrm{XCO}_{2} \_$satellite is the BRM or GOSAT L3 result, $\mathrm{XCO}_{2}^{-}$TCCON and $X \bar{C} \mathrm{O}_{2} \_$Satellite are the mean of $\mathrm{XCO}_{2}$ Satellite and $\mathrm{XCO}_{2}$ TCCON respectively.

\section{Results}

\subsection{Sensitivity Analysis}

\subsection{1. $\mathrm{CO}_{2}$ Concentration Sensitivity Analysis}

This section analyzes the sensitivities of $\mathrm{CO}_{2}$ concentration using the SCIATRAN model with a spectral resolution of $0.2 \mathrm{~cm}^{-1}$. Because retrieval accuracy must be less than $1 \%$, the change in the initial value in $\mathrm{CO}_{2}$ concentration sensitivity analysis was set at $0.5 \%$.

The retrieval band was $1565-1590 \mathrm{~nm}$, and the initial value of $\mathrm{CO}_{2}$ was $380 \mathrm{ppm}$. The sensitivities of $\mathrm{CO}_{2}$ concentration were analyzed without clouds and aerosol, and only changes in atmospheric radiation and $\mathrm{CO}_{2}$ concentration were examined. The basic parameters settings of SCIATRAN are shown in Table 1. 
Table 1. SCIATRAN parameters settings.

\begin{tabular}{cccccc}
\hline Parameters & Settings & Parameters & Settings & Parameters & Settings \\
\hline $\begin{array}{c}\text { Simulated } \\
\text { Altitude }\end{array}$ & $120 \mathrm{~km}$ & $\begin{array}{c}\text { Scattering } \\
\text { Mode }\end{array}$ & $\begin{array}{c}\text { Multiple } \\
\text { Scattering }\end{array}$ & Aerosol type & No \\
\hline $\begin{array}{c}\text { Observation } \\
\text { model }\end{array}$ & Nadir & Gas profile & $\begin{array}{c}\text { US Standard } \\
\text { Atmosphere }\end{array}$ & Cloud & No \\
\hline $\begin{array}{c}\text { Solar zenith } \\
\text { angle }\end{array}$ & $60^{\circ}$ & $\begin{array}{c}\text { Observation } \\
\text { nadir angle }\end{array}$ & $0^{\circ}$ & Solar spectra & Unity \\
\hline $\begin{array}{c}\text { Spectral } \\
\text { resolution }\end{array}$ & $0.2 \mathrm{~cm}^{-1}$ & $\begin{array}{c}\text { Linear } \\
\text { function }\end{array}$ & Gaussian & $\begin{array}{c}\text { Surface } \\
\text { albedo } \\
\text { (Lambert) }\end{array}$ & 0.2 \\
\hline $\begin{array}{c}\text { Integral } \\
\text { interval }\end{array}$ & $0.01 \mathrm{~nm}$ & $\begin{array}{c}\text { Integral } \\
\text { mode }\end{array}$ & Line-by-Line & $\begin{array}{c}\text { Atmospheric } \\
\text { model }\end{array}$ & Parallel \\
\hline
\end{tabular}

Figure 2 shows the normalized sensitivities of $\mathrm{CO}_{2}$ concentration after normalization of the solar normalized radiance rate, simplifying comparing the relative sensitivity between different bands. The trend of the normalized sensitivity was consistent with the rate of the radiance change.

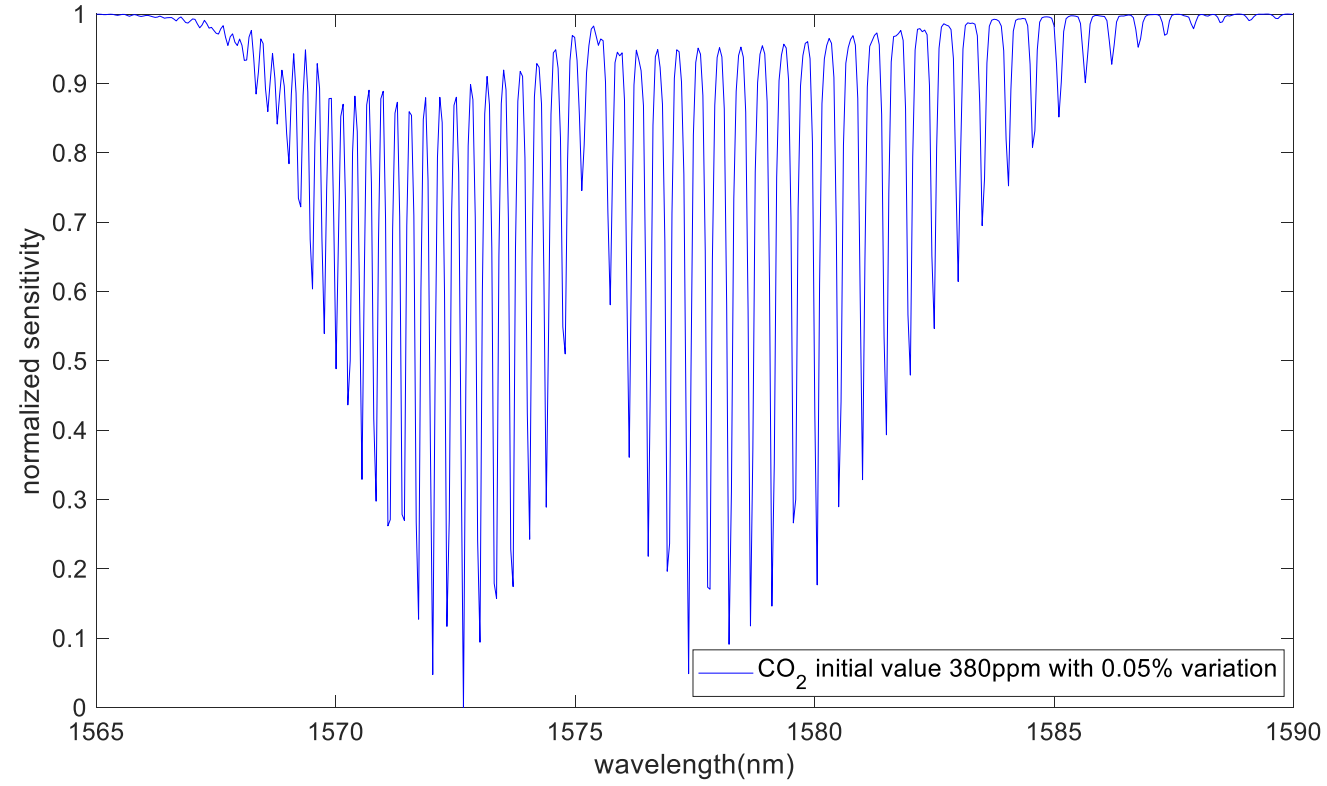

Figure 2. Normalized sensitivities when initial concentration and change in $\mathrm{CO}_{2}$ are $380 \mathrm{ppm}$ and $0.5 \%$, respectively.

Normalized sensitivities near the bands of 1565 and $1590 \mathrm{~nm}$ are close to 1, which means that these two bands are the least sensitive. Normalized sensitivity of $1572.5 \mathrm{~nm}$ is 0 , which means that the variation in $\mathrm{CO}_{2}$ concentration in this band is the most significant.

\subsubsection{Aerosol Sensitivity Analysis}

The normalized sensitivity of three types of aerosol parameters is addressed. There are season parameters, boundary layer aerosol types, and boundary layer visibility. Season parameters are fall/winter and spring/summer. For the boundary layer aerosol types, there are rural and urban. For the boundary layer visibility, there are 23 and $5 \mathrm{~km}$. The three parameters were combined into eight aerosol states, including the most general ones. They are (1) rural aerosol in fall and winter with boundary layer visibility of $23 \mathrm{~km}$; (2) rural aerosol in fall and winter with boundary layer visibility of $5 \mathrm{~km}$; (3) rural aerosol in spring and summer with boundary layer visibility of $23 \mathrm{~km}$;(4) rural aerosol in spring and summer 
with boundary layer visibility of $5 \mathrm{~km}$; (5)urban aerosol in fall and winter with boundary layer visibility of $23 \mathrm{~km}$;(6) urban aerosol in fall and winter with boundary layer visibility of $5 \mathrm{~km}$; (7) urban aerosol in spring and summer with boundary layer visibility of $23 \mathrm{~km}$; (8) urban aerosol in spring and summer with boundary layer visibility of $5 \mathrm{~km}$. Normalized sensitivities of eight aerosol states were analyzed by comparing the radiance difference between the eight aerosol states.

The four curves in Figure 3 represent the normalized sensitivity of the relative changes in fall and winter, and spring and summer parameters under four aerosol states: rural visibility of $23 \mathrm{~km}$, rural visibility of $5 \mathrm{~km}$, urban visibility of $23 \mathrm{~km}$, and urban visibility of $5 \mathrm{~km}$. The trends of the four curves were consistent with each other and indicated that variations in seasonal parameters had little effect on the relative variation of each band. Normalized urban $5 \mathrm{~km}$ sensitivities were lower than for the three other aerosol states. The overall trend of all curves showed that normalized sensitivities from 1565 to $1575 \mathrm{~nm}$ were lower than those from 1575 to $1590 \mathrm{~nm}$.
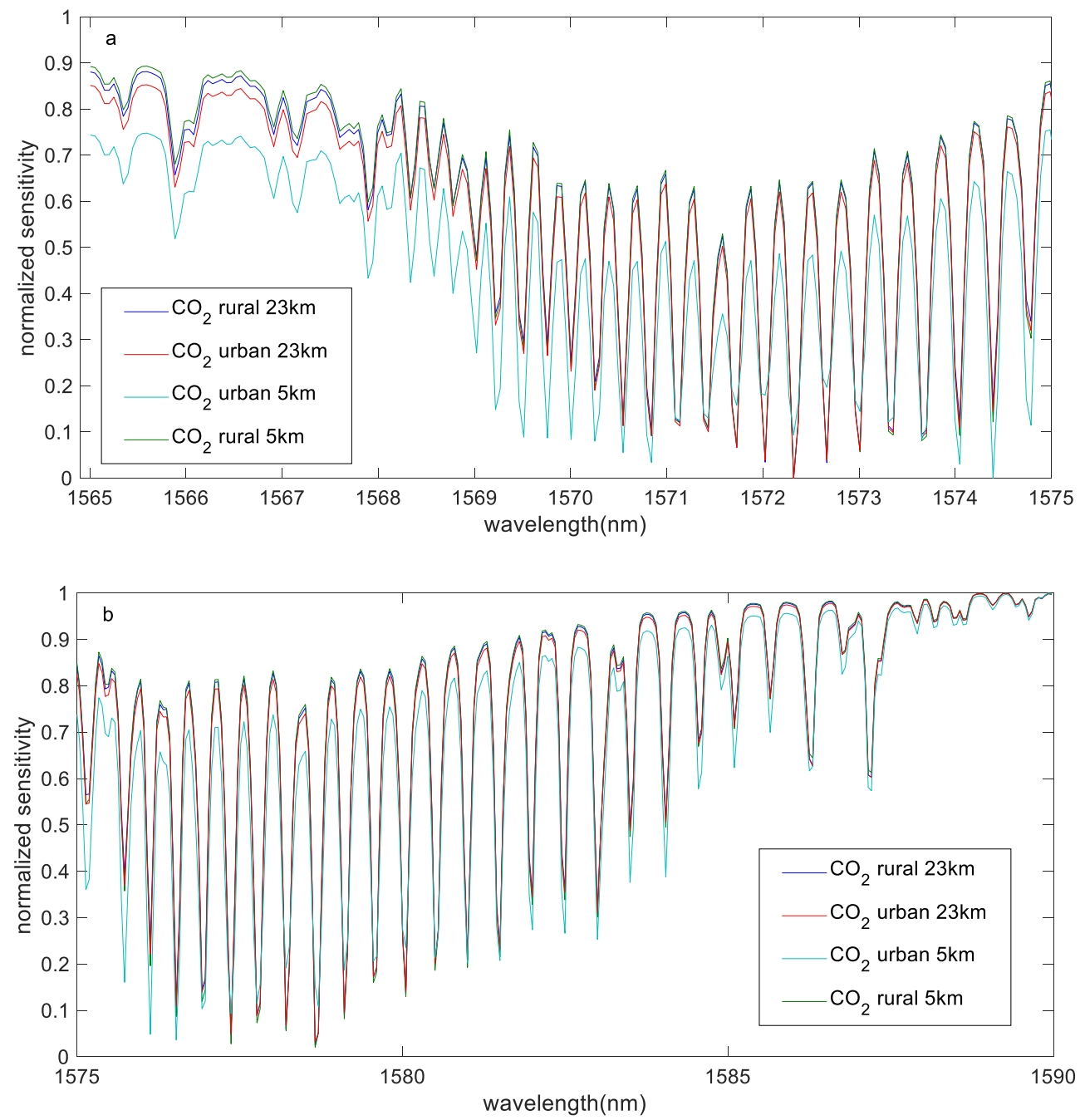

Figure 3. Normalized sensitivities of four aerosol states (rural $23 \mathrm{~km}$, rural $5 \mathrm{~km}$, urban $23 \mathrm{~km}$, and urban $5 \mathrm{~km}$ ). The spectral ranges of (a,b) are from 1565 to $1575 \mathrm{~nm}$ and from 1575 to $1590 \mathrm{~nm}$, respectively.

The four curves in Figure 4 represent normalized sensitivities of changes between urban and rural parameters under four aerosol states: fall/winter $23 \mathrm{~km}$, fall/winter $5 \mathrm{~km}$, spring/summer $23 \mathrm{~km}$, spring $/$ summer $5 \mathrm{~km}$. Results showed that the normalized sensitivity of the four aerosol states was almost the same between urban and rural types, indicating that urban and rural aerosol types have a minor effect on the relative changes between different bands. 

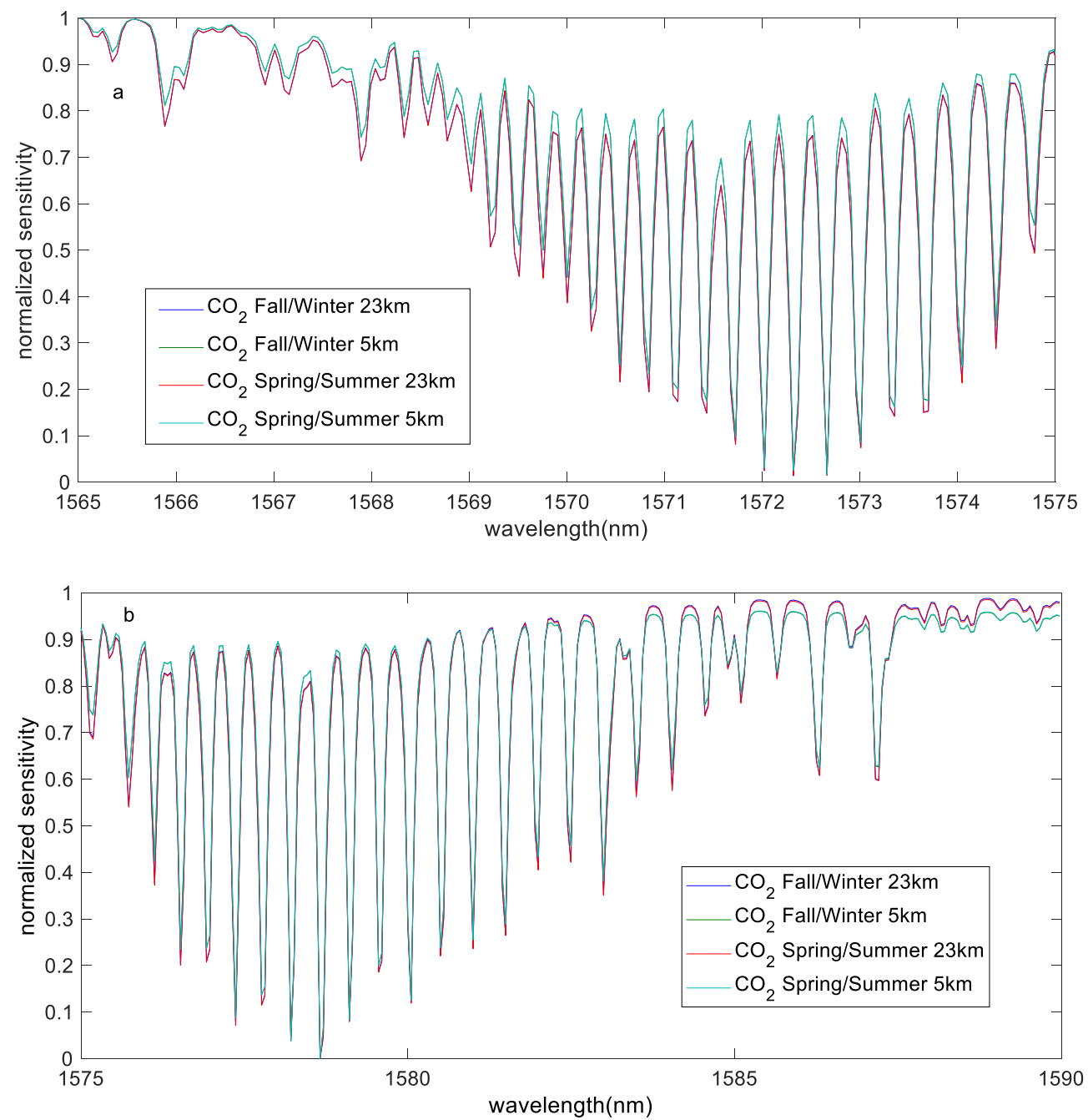

Figure 4. Normalized sensitivities of the changes between the urban and rural types of four aerosol states (fall/winter $23 \mathrm{~km}$, fall/winter $5 \mathrm{~km}$, spring/summer $23 \mathrm{~km}$, spring/summer $5 \mathrm{~km}$ ). The spectral ranges of (a,b) are from 1565 to $1575 \mathrm{~nm}$ and from 1575 to $1590 \mathrm{~nm}$, respectively.

Figure 5 shows the normalized sensitivities of the change boundary layer visibility 23 and $5 \mathrm{~km}$ parameters under four aerosol states: fall/ winter rural, fall/winter urban, spring/summer rural, and spring/summer urban. Trends of fall/winter rural and fall/winter urban were the same. In addition, spring/summer rural and spring/summer urban trends were approximately the same. Therefore, the relative variation between fall/winter and spring/summer was not significant. Compared with Figures 3 and 4, boundary layer visibility parameters had the most significant relative changes between different bands.

The normalized sensitivities of the season parameters, the boundary layer aerosol types, and the boundary layer visibility are analyzed in Figures $3-5$. The relative variation between season parameters was not significant.

The boundary layer aerosol type had a minor influence on the relative variation among the $\mathrm{CO}_{2}$ bands. The boundary layer visibility was the most critical factor affecting the relative variation of each band.

\subsubsection{Albedo Sensitivity Analysis}

The accuracy of global surface albedo products is an uncertain factor that may cause significant error sources in the retrieval of $\mathrm{CO}_{2}$. Therefore, it is necessary to analyze the sensitivity of surface albedo and find the channel with little difference in surface albedo in 
the retrieval band. Then, we can minimize the influence of surface albedo on the retrieval of $\mathrm{CO}_{2}$ by the BRM.

In the sensitivity analysis of surface albedo, the values of other parameters are constant, and only the surface albedo is changed. The surface albedo was constant with wavelength, and the initial values of $\mathrm{CO}_{2}$ were $380 \mathrm{ppm}$. Other SCIATRAN model parameters were the same as those set in Table 1 . The surface albedo was set to $0.05,0.1,0.15,0.2,0.3$, and 0.4 .

Figure 6 shows a consistent trend in normalized sensitivities of the six surface albedos in the $\mathrm{CO}_{2}$ retrieval bands. Results indicated that the effect of different surface albedo on the relative changes between various bands was the same. Therefore, the influence of surface albedo on retrieval can be significantly restrained using the BRM by selecting the band with the same normalized sensitivities.

\subsubsection{Water Vapor Profile Sensitivity Analysis}

Water vapor is the only gas that interferes with $\mathrm{CO}_{2}$ retrieval in the near-infrared band. Water vapor exists in the middle and lower troposphere, and its concentration rapidly decreases with an increase in altitude. The water vapor absorption of solar radiation in the near-infrared band is relatively weak compared to scattering by aerosol. However, it is still a significant factor affecting retrieval accuracy. The satellite retrieval error of the water vapor profile was below $10 \%$ [34]. Therefore, the increase in water vapor profile was set to $5 \%$ and $10 \%$. The influences of the variation in water vapor profile were simulated, and normalized sensitivities were established.

Figure 7 shows the normalized sensitivities of the water vapor profile with an increase of $5 \%$ to $10 \%$. Results indicated that the influence of water vapor could be reduced by removing the band with a water value of normalized sensitivity between 0.8 and 0 .

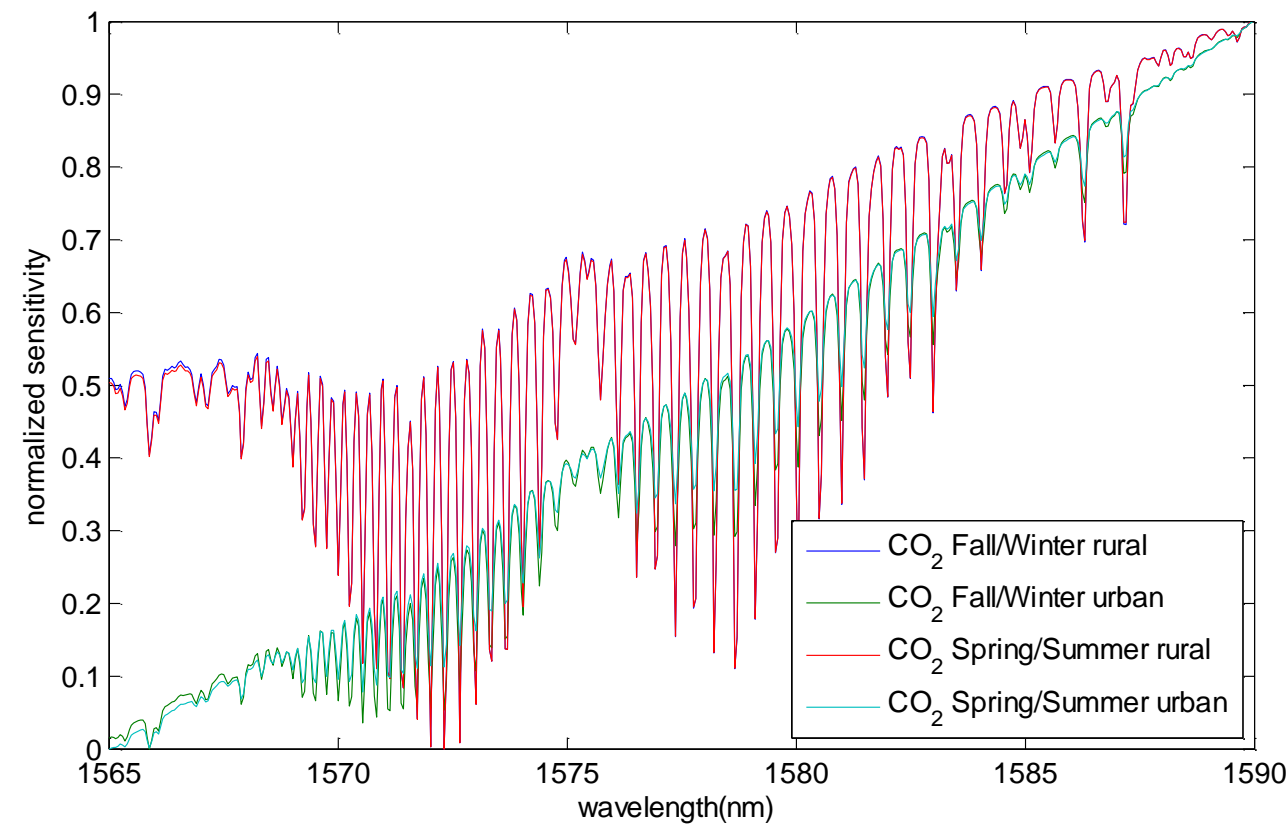

Figure 5. Normalized sensitivities of four aerosol states of fall/winter rural, fall/winter urban, spring/summer rural, and spring/summer urban between $\mathrm{CO}_{2}$ visibilities of 23 and $5 \mathrm{~km}$. 

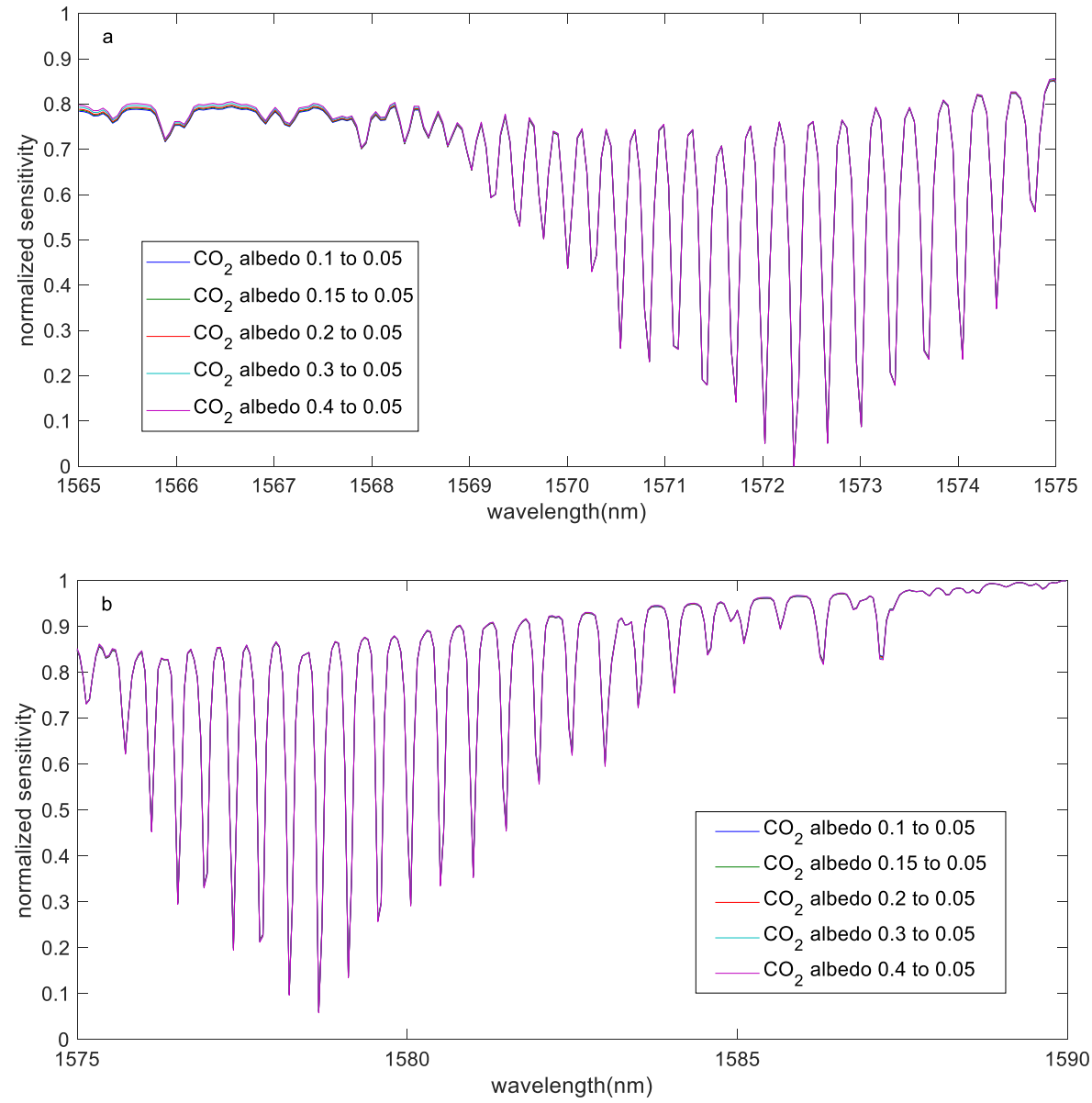

Figure 6. Normalized sensitivity values of six surface albedos. The spectral ranges of $(\mathbf{a}, \mathbf{b})$ are from 1565 to $1575 \mathrm{~nm}$ and from 1575 to $1590 \mathrm{~nm}$, respectively.

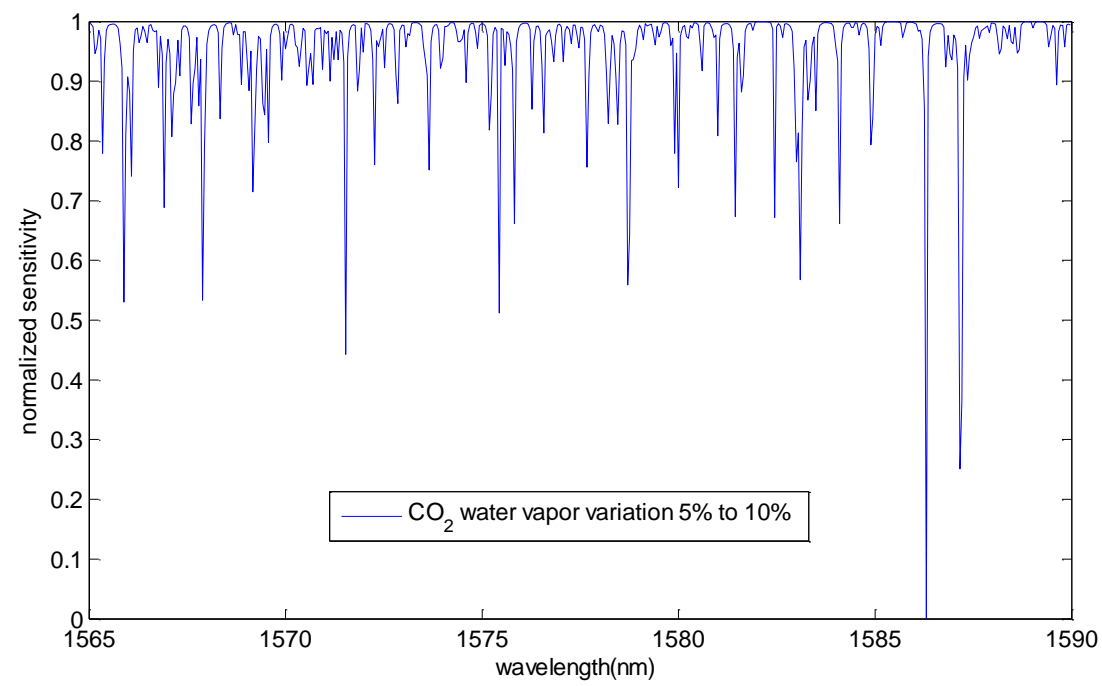

Figure 7. Normalized sensitivities of water vapor profile with increase of $5 \%$ to $10 \%$.

\subsection{Retrieval Channel Selection}

Retrieval channels were selected on the basis of the normalized sensitivities of $\mathrm{CO} 2$ concentration, aerosol, surface albedo, and water vapor. Normalized sensitivities of $\mathrm{CO}_{2}$ concentration, surface albedo, and aerosol are shown in Figure 8. Normalized sensitivities of aerosol are the average of the normalized sensitivity of the eight aerosol states. According 
to these normalized sensitivities, $\mathrm{CO}_{2}$ high- and low-sensitivity channels were selected using the BRM.

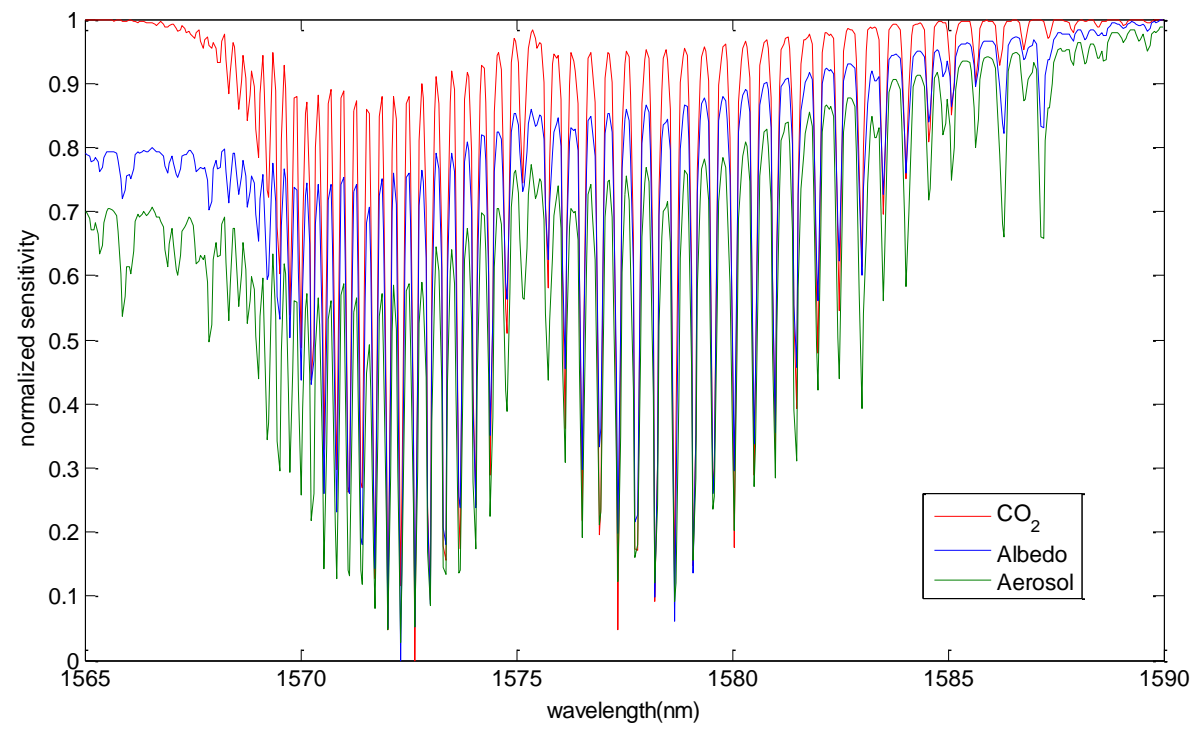

Figure 8. Normalized sensitivity of $\mathrm{CO}_{2}$ concentration, surface albedo, and aerosol.

The high- and low-sensitivity channels were determined as follows:

(1) Bands with low albedo sensitivities from 0.5 to 1 were preselected channels, and those with high albedo sensitivities from 0 to 0.5 were discarded channels.

(2) Bands with low aerosol sensitivities from 0.5 to 1 were preselected channels, and those with high aerosol sensitivities from 0 to 0.5 were discarded channels.

(3) Removing high sensitivities water vapor channels in which the normalization sensitivities are between 0 and 0.8 .

(4) After these three steps, the normalized sensitivities of $\mathrm{CO}_{2}$ concentration of preselected channels range from 0.64 to 1 . Therefore, low-sensitivity channels of $\mathrm{CO}_{2}$ were set from 0.9 to 1 . High-sensitivity channels of $\mathrm{CO}_{2}$ were set from 0.64 to 0.9 .

After channel selection, 91 high-sensitivity channels and 285 low-sensitivity channels were obtained in $\mathrm{CO}_{2}$ retrieval bands from 1560 to 1590 nm, as shown in Figure 9.

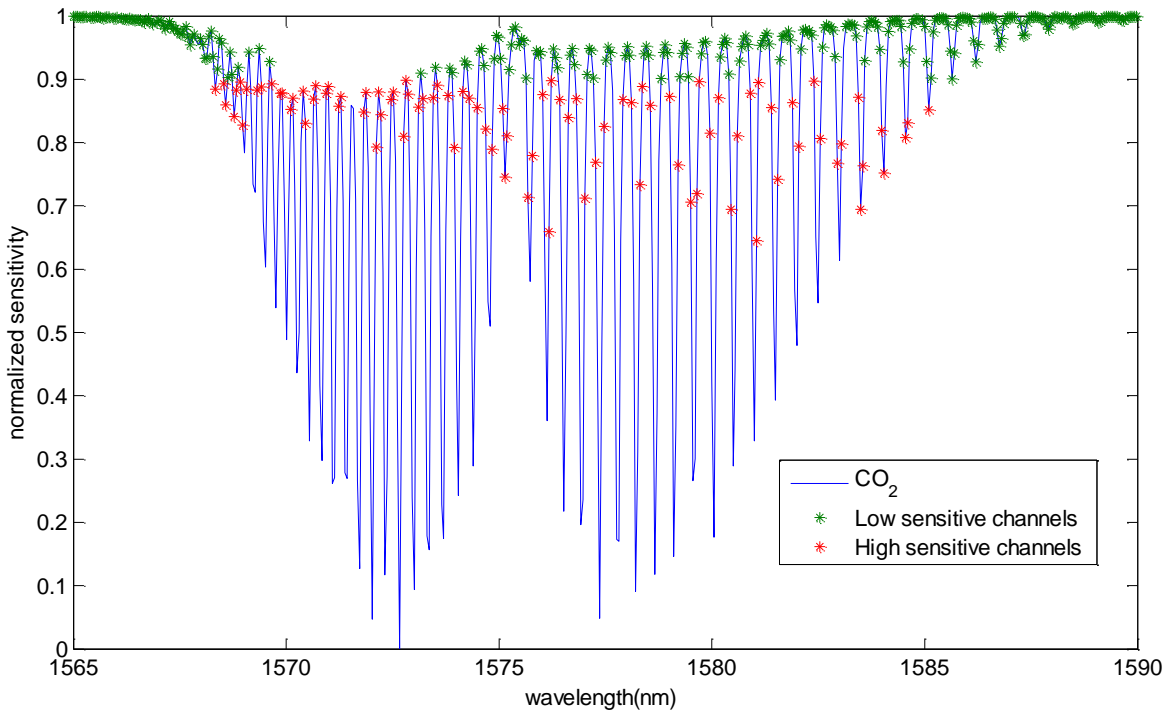

Figure 9. 91 high-sensitivity channels and 285 low-sensitivity channels obtained in $\mathrm{CO}_{2}$ retrieval band from 1560 to $1590 \mathrm{~nm}$. 


\subsection{Retrieval Error Analysis}

(1) Aerosol retrieval error analysis

In aerosol retrieval error analysis, reference radiance is calculated without clouds and aerosol, but with a surface albedo of 0.2 . The initial $\mathrm{CO}_{2}$ concentration was set to $380 \mathrm{ppm}$. We calculated a $\mathrm{CO}_{2}$ concentration value for each type of aerosol, resulting in the radiance curves closest to the reference radiance. The relative difference between this value and the initial $\mathrm{CO}_{2}$ concentration was the aerosol retrieval error in that condition. These eight aerosol states are eight aerosol conditions in sensitivity analysis, namely, fall/winter rural $23 \mathrm{~km}$, fall/winter rural $5 \mathrm{~km}$, spring/summer rural $23 \mathrm{~km}$, spring/summer rural $5 \mathrm{~km}$, fall/winter urban $23 \mathrm{~km}$, fall/winter urban $5 \mathrm{~km}$, spring/summer urban $23 \mathrm{~km}$, and spring/summer urban $5 \mathrm{~km}$. Other SCIATRAN parameters were the same as the default parameters in Table 1.

Aerosol retrieval errors are shown in Table 2. The BRM has a better-restrained effect on the aerosol retrieval error compared with the optimal estimation method. The overall retrieval error decreased by $2.5 \%$. The largest decrease was $3.8 \%$ in the aerosol state of fall/winter rural $5 \mathrm{~km}$. Results show that the boundary layer visibility parameter had a more significant influence on the retrieval error.

Table 2. Aerosol retrieval error.

\begin{tabular}{ccccc}
\hline \multirow{2}{*}{$\begin{array}{c}\text { Season } \\
\text { Parameters }\end{array}$} & $\begin{array}{c}\text { Boundary Layer } \\
\text { Aerosol Types }\end{array}$ & $\begin{array}{c}\text { Boundary Layer } \\
\text { Visibility (km) }\end{array}$ & BRM Error (\%) & OEM Error (\%) \\
\hline \multirow{3}{*}{ Spring/summer } & Urban & $23 \mathrm{~km}$ & -5.6 & -8.3 \\
\cline { 2 - 4 } & \multirow{2}{*}{ Rural } & $5 \mathrm{~km}$ & -12.4 & -13.9 \\
\cline { 2 - 5 } & \multirow{2}{*}{ Urban } & $23 \mathrm{~km}$ & -6.7 & -7.8 \\
\cline { 3 - 5 } Fall/winter & \multirow{2}{*}{ Rural } & $5 \mathrm{~km}$ & -11.1 & -13.6 \\
\cline { 3 - 5 } & & $23 \mathrm{~km}$ & -6.4 & -9.4 \\
\cline { 3 - 5 } & & $5 \mathrm{~km}$ & -12.4 & -14.1 \\
\hline
\end{tabular}

(2) Albedo retrieval error analysis

In the retrieval error analysis of surface albedo, the reference radiance was calculated without cloud and aerosol and with a surface albedo of 0.2. The surface albedo error analysis set variation to $5 \%, 10 \%, 20 \%$, and $30 \%$.

We calculated a $\mathrm{CO} 2$ concentration value for each surface albedo change, resulting in the radiance curves closest to the reference radiance. The relative difference between this value and the initial $\mathrm{CO}_{2}$ concentration is the albedo retrieval error in that condition.

As shown in Table 3, the retrieval error of the BRM was compared with that of the optimal estimation method. The retrieval error increased with the change in surface albedo. For the OEM, when the change in surface albedo was $5 \%$, the retrieval error of $\mathrm{CO}_{2}$ was $3.36 \%$. When the change in surface albedo was 30\%, the retrieval error of $\mathrm{CO}_{2}$ reached $22.8 \%$. Results showed that the BRM could effectively restrain the retrieval error with surface albedo change. When the change in surface albedo was less than $20 \%$, the retrieval error of the BRM was less than 1\%. Results demonstrated that the BRM in this work could effectively restrain the retrieval error caused by surface albedo.

\subsection{Validation Result}

\subsubsection{Park Falls}

GOSAT L1B data within $4^{\circ}$ around this site were selected for retrieval. The number of matching days from April to September 2011 was 82 . Figure 10 shows the daily retrieval data of TCCON and the daily retrieval results from the BRM in Park Falls. The CORR 
between the daily retrieval data of TCCON and the daily retrieval results from the BRM was 0.83 . The MB, MAB, and RMSE were $-0.47,2.15$, and $2.76 \mathrm{ppm}$, respectively.

Table 3. Albedo retrieval error.

\begin{tabular}{ccc}
\hline Changes in Surface Albedo & BRM Error (\%) & OEM Error (\%) \\
\hline $5 \%$ & 0.45 & 3.36 \\
\hline $10 \%$ & 0.74 & 6.32 \\
\hline $20 \%$ & 1.03 & 13.6 \\
\hline $30 \%$ & 4.79 & 22.8 \\
\hline
\end{tabular}

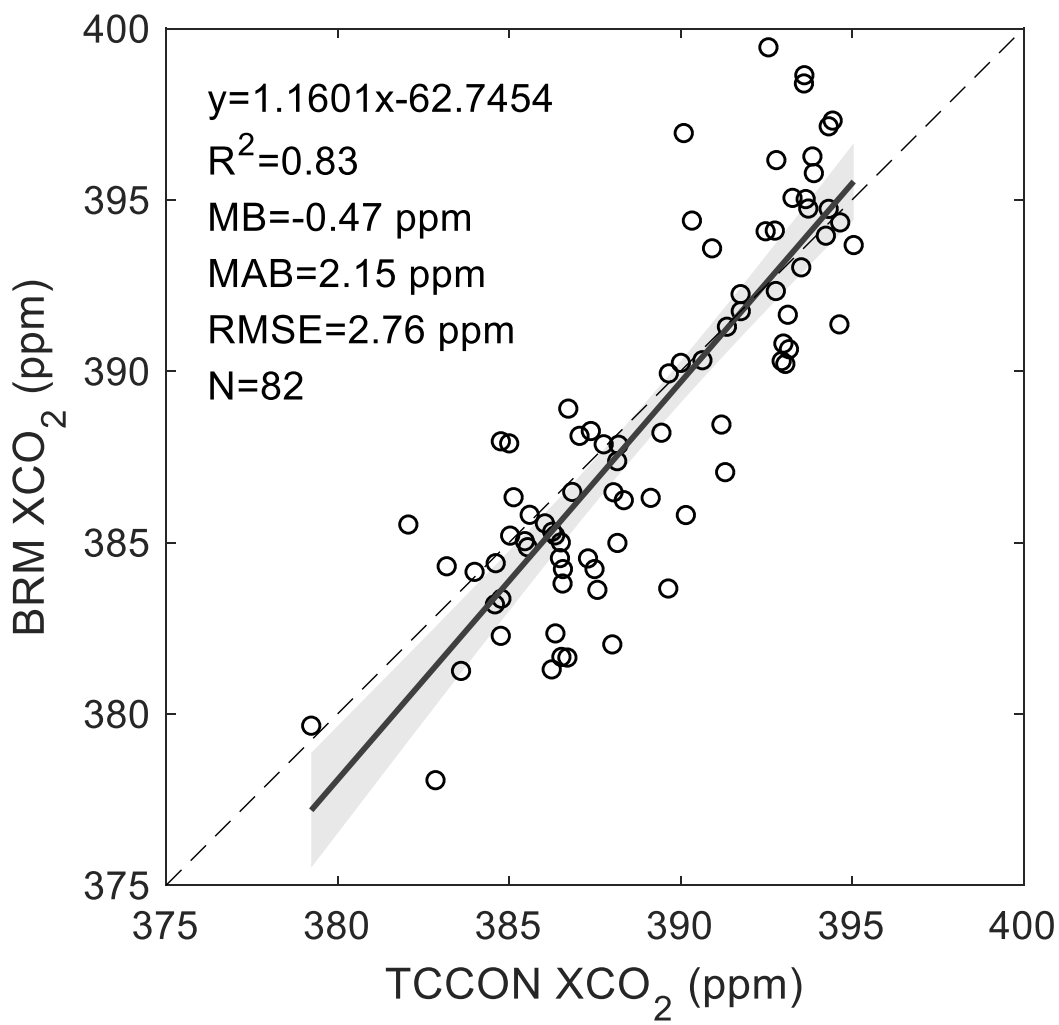

Figure 10. Daily retrieval data of TCCON and daily retrieval results from BRM at Park Falls site. Solid line shows linear regression results. Gray shade represents the $95 \%$ confidence interval.

Figure 11 shows monthly retrieval results of BRM, and GOSAT L3 monthly results were used to compare with the monthly retrieval results by the TCCON in Park Falls. The CORR between the monthly retrieval data of BRM (GOSAT L3) and TCCON was $0.94(0.90)$. The MB, MAB, and RMSE of BRM and TCCON were $-0.10,1.41$, and $1.81 \mathrm{ppm}$, respectively. The MB, MAB, and RMSE of GOSAT L3 and TCCON were $-0.57,1.77$, and $2.01 \mathrm{ppm}$, respectively. BRM and GOSAT L3 results at the Park Falls site had high correlation with the TCCON results. The MB, MAB, and RMSE of the BRM results were lower than the corresponding errors between GOSAT L3 and TCCON.

\subsubsection{Wollongong}

The GOSAT L1B data within $2^{\circ}$ around this site were selected for retrieval. The number of matching days from April to September 2011 was 35.

Figure 12 shows the daily retrieval data of TCCON and the daily retrieval results from the BRM in the Wollongong site. The CORR between the daily retrieval data of TCCON and daily retrieval results from the BRM was 0.53 . The MB, MAB, and RMSE were -0.18 , 1.08 and $1.29 \mathrm{ppm}$, respectively. 

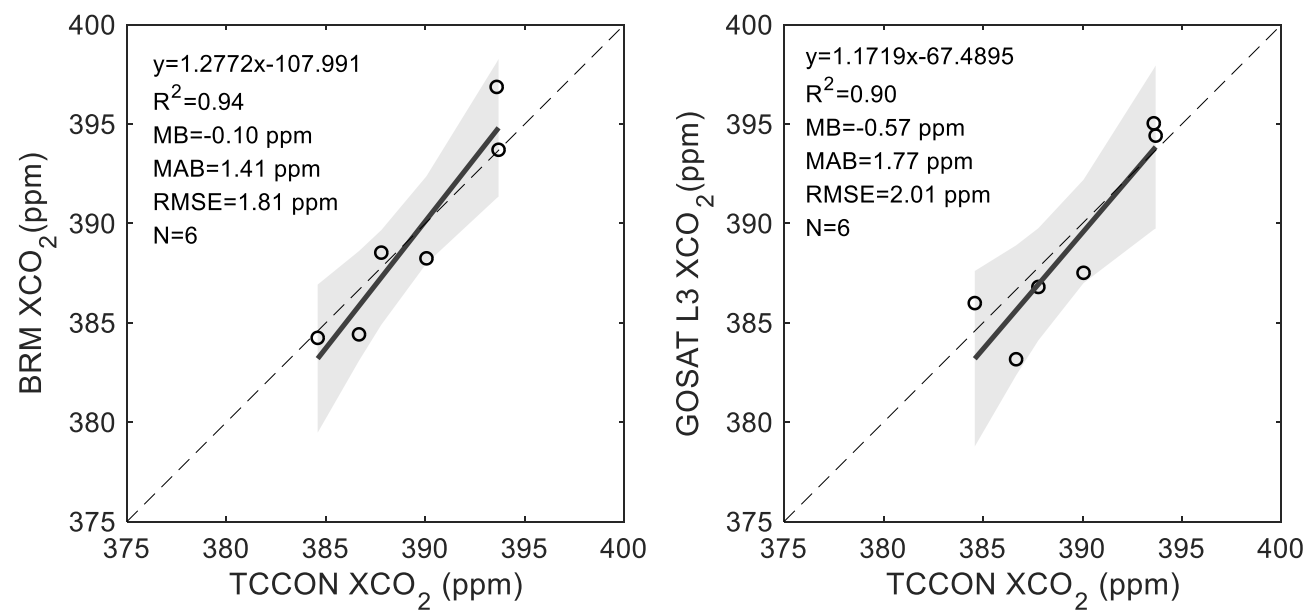

Figure 11. Monthly retrieval data of TCCON and GOSAT L3 monthly results used to compare with monthly retrieval results by BRM at Park Falls site. Solid line shows linear regression results. Gray shade represents $95 \%$ confidence interval.

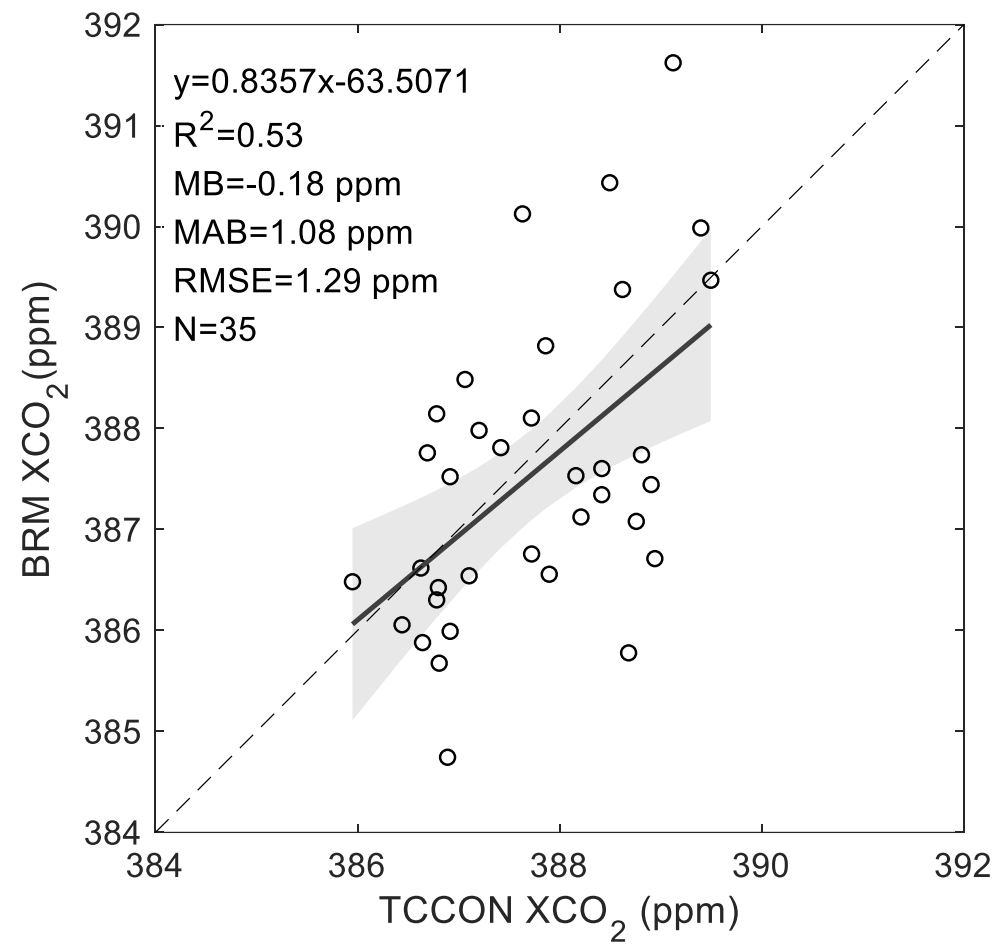

Figure 12. Daily retrieval data of TCCON and daily retrieval results from BRM at Wollongong site. Solid line shows linear regression results. Gray shade represents 95\% confidence interval.

Figure 13 shows monthly retrieval results of TCCON. GOSAT L3 monthly results were used to compare with the monthly retrieval results by the BRM at the Wollongong site.

The CORR between the monthly retrieval data of BRM (GOSAT L3) and TCCON was 0.68 (0.45). The MB, MAB, and RMSE of BRM and TCCON were $-0.38,0.68$, and $0.79 \mathrm{ppm}$, respectively. The MB, MAB, and RMSE of GOSAT L3 and TCCON were 1.39, 1.39, and $1.59 \mathrm{ppm}$, respectively. In the Wollongong site, results of the BRM had higher correlation with TCCON results than those of the GOSAT L3. The MB, MAB, and RMSE of the BRM results were lower than the corresponding errors between GOSAT L3 and TCCON. 

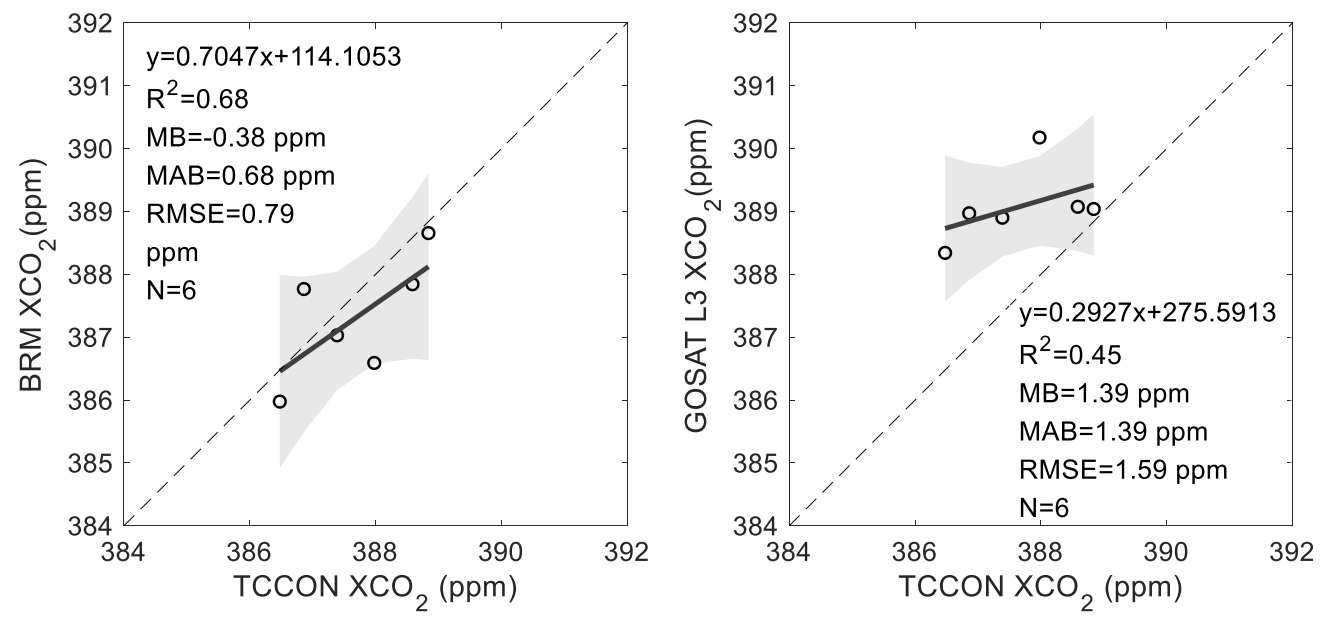

Figure 13. Monthly retrieval data of TCCON and GOSAT L3 monthly results used to compare with monthly retrieval results by BRM at Wollongong site. Solid line shows linear regression results. Gray shade represents $95 \%$ confidence interval.

\section{Discussion}

This work presents normalized sensitivities for selecting channels to retrieve $\mathrm{CO}_{2}$ concentration in the near-infrared band. The normalized sensitivities of $\mathrm{CO}_{2}$ concentration, aerosol, surface albedo, and the water vapor profile were analyzed using the SCIATRAN model. On the basis of normalization sensitivities, the BRM from the OEM improved with channel selection and the band ratio process. The retrieval errors of the two methods were compared.

The normalized sensitivities of $\mathrm{CO}_{2}$ concentration, aerosol, surface albedo, 91 highsensitivity channels, and 285 low-sensitivity channels were obtained. In the retrieval error analysis of aerosol, BRM was more effective in restraining the influence of aerosol than OEM was, and the retrieval error was reduced by $2.5 \%$ overall. In the retrieval error analysis of surface albedo, the BRM was more effective in restraining surface albedo's influence than the OEM was. The BRM could effectively reduce the retrieval error of $\mathrm{CO}_{2}$ when the relative change in surface albedo was less than $20 \%$.

We validated the BRM retrieval results with two TCCON sites and GOSAT L3 results. Results showed that the CORR between daily retrieval data of TCCON with the daily retrieval results of the BRM was higher in Park Falls than that in Wollongong. BRM and GOSAT L3 monthly retrieval data were used to compare with TCCON. Results showed that the CORR, MB, MAB, and RMSE of the monthly retrieval data of BRM had good agreement with the TCCON in both Park Falls and Wollongong.

The previous OEM used all bands to retrieve a large amount of hyperspectral data and was restricted by the accuracy of prior knowledge [35]. Accurate $\mathrm{XCO}_{2}$ retrieval usually requires large computational effort [36]. The OEM method uses all spectra, such as NIES [21], ACOS [17], UoL-FP [18], RemoTeC [19], and the UoL-FP algorithm [22] to retrieve. The BRM was introduced to solve these two problems. The selection of retrieval channels was used to reduce the redundancy of hyperspectral data with BRM. Neglecting aerosol scattering in the retrieval can often lead to higher than $1 \%$ (about $4 \mathrm{ppm}$ ) $\mathrm{XCO}_{2}$ errors $[37,38]$. The BRM was used to restrain redundancy and eliminate the influence of surface albedo and aerosol. The choice of non- $\mathrm{CO}_{2}$ and $\mathrm{CO}_{2}$ absorption channels were compared and analyzed only considering surface reflectance [39]. In our study, the band ratio process considered the effects of aerosols, albedo, and water vapor.

However, some limitations are worth noting. Although we are supported statistically, the sensitivity analysis of instrument performance parameters and more aerosol parameters was lacking. Therefore, future work should include follow-up work designed to evaluate the sensitivity analysis of instrument performance parameters, more aerosol parameters, and whether they can continue to be used to improve. 


\section{Conclusions}

Prior work documented the necessity to restrain the influence of surface albedo and aerosol when a highly accurate method for the retrieval of $\mathrm{CO}_{2}$ is needed [40-42]. Surface albedo and aerosol are known values in these studies. However, high-accuracy surface albedo and aerosols are difficult to obtain in different areas. Therefore, this study indicated that the gained benefits can effectively restrain the influence of surface albedo and aerosol.

We validated the BRM retrieval results with two TCCON sites and GOSAT L3 products. Results showed that the CORR, MB, MAB, and RMSE of the monthly retrieval data of BRM showed good agreement in the TCCON in both Park Falls and Wollongong. These results indicated that BRM is more applicable and robust.

Aerosols and surface albedo affect atmospheric carbon dioxide retrieval in the nearinfrared band. There are many studies on atmospheric carbon dioxide retrieval methods. No matter which method is used, the primary purpose is to reduce the influence of surface albedo and aerosol, and especially aerosol. Rapid and changeable aerosols make the aerosols in the retrieval process particularly essential and challenging.

This method can be applied to retrieving surface albedo and aerosol patterns in different global regions in future work. Nevertheless, the method should be tested on different satellite data, including GOSAT and OCO-2.

Author Contributions: Conceptualization, L.Z. and S.C.; methodology, L.Z. and T.C.; software, L.Z.; validation, L.Z. and Y.X.; formal analysis, L.Z. and Y.X.; writing-original draft preparation, L.Z.; writing-review and editing, L.Z., T.C. and Y.X.; funding acquisition, Y.X. All authors have read and agreed to the published version of the manuscript.

Funding: This work was supported in part by the National Natural Science Foundation of China (NSFC) under Grant 41871260 and supported by the Fundamental Research Funds for the Central Universities under Grant 2022QN1084. We are grateful to A. Rozanov for supplying the radiative transfer model SCIATRAN.

Acknowledgments: This work was supported in part by the National Natural Science Foundation of China (NSFC) under grant 41871260 . We are grateful to A. Rozanov for supplying the radiative transfer model SCIATRAN. TCCON data were obtained from the TCCON Data Archive hosted by CaltechDATA at https:/ / tccondata.org accessed on 6 January 2022. We thank TCCON PIs for the TCCON measurements at Park Falls and Wollongong stations. We thank the GOSAT team for the Level $1 \mathrm{~B}$ and $\mathrm{L} 3 \mathrm{CO}_{2}$ products.

Conflicts of Interest: The authors declare no conflict of interest.

\section{References}

1. Wu, L.; Hasekamp, O.; Hu, H.; Landgraf, J.; Butz, A.; aan de Brugh, J.; Aben, I.; Pollard, D.F.; Griffith DW, T.; Feist, D.G.; et al. Carbon dioxide retrieval from OCO-2 satellite observations using the RemoTeC algorithm and validation with TCCON measurements. Atmos. Meas. Tech. 2018, 11, 3111-3130. [CrossRef]

2. Buchwitz, M.; de Beek, R.; Noël, S.; Burrows, J.P.; Bovensmann, H.; Bremer, H.; Bergamaschi, P.; Körner, S.; Heimann, M. Carbon monoxide, methane and carbon dioxide columns retrieved from SCIAMACHY by WFM-DOAS: Year 2003 initial data set. Atmos. Chem. Phys. 2005, 5, 3313-3329. [CrossRef]

3. Yokota, T.; Yoshida, Y.; Eguchi, N.; Ota, Y.; Tanaka, T.; Watanabe, H.; Maksyutov, S. Global Concentrations of $\mathrm{CO}_{2}$ and $\mathrm{CH}_{4}$ Retrieved from GOSAT: First Preliminary Results. Sci. Online Lett. Atmos. 2009, 5, 160-163. [CrossRef]

4. Wunch, D.; Wennberg, P.O.; Osterman, G.; Fisher, B.; Naylor, B.; Roehl, C.M.; O’Dell, C.; Mandrake, L.; Viatte, C.; Kiel, M.; et al Comparisons of the Orbiting Carbon Observatory-2 (OCO-2) $\mathrm{XCO}_{2}$ measurements with TCCON. Atmos. Meas. Tech. 2017, 10, 2209-2238. [CrossRef]

5. Liu, Y.; Cai, Z.; Yang, D.; Zheng, Y.; Duan, M.; Lü, D. Effects of spectral sampling rate and range of $\mathrm{CO}_{2}$ absorption bands on $\mathrm{XCO}_{2}$ retrieval from TanSat hyperspectral spectrometer. Chin. Sci. Bull. 2014, 59, 1485-1491. [CrossRef]

6. Kuze, A.; Suto, H.; Nakajima, M.; Hamazaki, T. Thermal and near infrared sensor for carbon observation Fourier-transform spectrometer on the Greenhouse Gases Observing Satellite for greenhouse gases monitoring. Appl. Opt. 2009, 48, 6716-6733. [CrossRef]

7. Eldering, A.; Boland, S.; Solish, B.; Crisp, D.; Kahn, P.; Gunson, M. High precision atmospheric $\mathrm{CO}_{2}$ measurements from space: The design and implementation of OCO-2. In Proceedings of the 2012 IEEE Aerospace Conference, Big Sky, MT, USA, 3-10 March 2012; pp. 1-10. [CrossRef] 
8. Oshchepkov, S.; Bril, A.; Yokota, T.; Wennberg, P.; Deutscher, N.; Wunch, D.; Toon, G.C.; Yoshida, Y.; O’Dell, C.W.; Crisp, D.; et al. Effects of atmospheric light scattering on spectroscopic observations of greenhouse gases from space. Part 2: Algorithm intercomparison in the GOSAT data processing for $\mathrm{CO}_{2}$ retrievals over TCCON sites. J. Geophys. Res. Atmos. 2013, 118, 1493-1512. [CrossRef]

9. Thompson, D.R.; Benner, D.C.; Brown, L.R.; Crisp, D.; Devi, V.M.; Jiang, Y.; Natraj, V.; Oyafuso, F.; Sung, K.; Wunch, D.; et al. Atmospheric validation of high accuracy $\mathrm{CO}_{2}$ absorption coefficients for the OCO-2 mission. J. Quant. Spectrosc. Radiat. Transf. 2012, 113, 2265-2276. [CrossRef]

10. Basu, S.; Guerlet, S.; Butz, A.; Houweling, S.; Hasekamp, O.; Aben, I.; Krummel, P.; Steele, P.; Langenfelds, R.; Torn, M.; et al Global $\mathrm{CO}_{2}$ fluxes estimated from GOSAT retrievals of total column $\mathrm{CO}_{2}$. Atmos. Chem. Phys. 2013, 13, 8695-8717. [CrossRef]

11. Chevallier, F.; Palmer, P.I.; Feng, L.; Boesch, H.; O'Dell, C.W.; Bousquet, P. Toward robust and consistent regional CO2 flux estimates from in situ and spaceborne measurements of atmospheric $\mathrm{CO}_{2}$. Geophys. Res. Lett. 2014, 41, 1065-1070. [CrossRef]

12. Sayer, A.M.; Thomas, G.E.; Grainger, R.G.; Carboni, E.; Poulsen, C.; Siddans, R. Use of MODIS-derived surface reflectance data in the ORAC-AATSR aerosol retrieval algorithm: Impact of differences between sensor spectral responses functions. Remote Sens. Environ. 2012, 116, 177-188. [CrossRef]

13. Buchwitz, M.; Rozanov, V.V.; Burrows, J.P. A correlated-k distribution scheme for overlapping gases suitable for retrieval of atmospheric constituents from moderate resolution radiance measurements in the visible/near-infrared spectral region. J. Geophys. Resphys. Res. 2000, 105, 15247-15309. [CrossRef]

14. Rodgers, C.D. Inverse Methods for Atmospheric Sounding: Theory and Practice; World Scientific: Singapore, 2000.

15. Frankenberg, C.; Platt, U.; Wagner, T. Iterative maximum a posteriori (IMAP)-DOAS for retrieval of strongly absorbing trace gases: Model studies for $\mathrm{CH} 4$ and $\mathrm{CO} 2$ retrieval from near infrared spectra of SCIAMACHY onboard ENVISAT. Atmos. Chem. Phys. 2005, 5, 9-22. [CrossRef]

16. Barkley, M.P.; Monks, P.S.; Hewitt, A.J.; Machida, T.; Desai, A.; Vinnichenko, N.; Nakazawa, T.; Yu Arshinov, M.; Fedoseev, N.; Watai, T. Assessing the near surface sensitivity of SCIAMACHY atmospheric CO2 retrieved using (FSI) WFM-DOAS. Atmos. Chem. Phys. Discuss. 2007, 7, 2477-2530.

17. O'Dell, C.W.; Eldering, A.; Wennberg, P.O.; Crisp, D.; Gunson, M.R.; Fisher, B.; Frankenberg, C.; Kiel, M.; Lindqvist, H.; Mandrake, L.; et al. Improved retrievals of carbon dioxide from Orbiting Carbon Observatory-2 with the version 8 ACOS algorithm. Atmos. Meas. Tech. 2018, 11, 6539-6576. [CrossRef]

18. Reuter, M.; Buchwitz, M.; Schneising, O.; Noël, S.; Rozanov, V.; Bovensmann, H.; Burrows, J.P. A Fast Atmospheric Trace Gas Retrieval for Hyperspectral Instruments Approximating Multiple Scattering-Part 1: Radiative Transfer and a Potential OCO-2 $\mathrm{XCO}_{2}$ Retrieval Setup. Remote Sens. 2017, 9, 1159. [CrossRef]

19. Wu, L.; Aben, I.; Haekamp, O.P. Product User Guide and Specification (PUGS)_ANNEX B for Products CO2_GOS_SRFP, CH4_GOS_SRFP (v2.3.8, 2009-2018). 2019. Available online: http://wdc.dlr.de/C3S_312b_Lot2/Documentation/GHG/PUGS/ C3S_D312b_Lot2.3.2.3-v1.0_PUGS-GHG_ANNEX-B_v3.1.pdf (accessed on 17 August 2020).

20. Iwasaki, C.; Imasu, R.; Bril, A.; Oshchepkov, S.; Rokotyan, N. Optimization of the Photon Path Length Probability Density Function-Simultaneous (PPDF-S) Method and Evaluation of $\mathrm{CO}_{2}$ Retrieval Performance Under Dense Aerosol Conditions. Sensors 2019, 19, 1262. [CrossRef] [PubMed]

21. Inoue, M.; Morino, I.; Uchino, O.; Nakatsuru, T. Bias corrections of GOSAT SWIR $\mathrm{XCO}_{2}$ and $\mathrm{XCH}_{4}$ with TCCON data and their evaluation using aircraft measurement data. Atmos. Meas. Tech. 2016, 9, 3491-3512. [CrossRef]

22. Yang, D.; Boesch, H.; Liu, Y.; Somkuti, P.; Cai, Z.; Chen, X.; Di Noia, A.; Lin, C.; Lu, N.; Lyu, D.; et al. Toward high precision $\mathrm{XCO}_{2}$ retrievals from TanSat observations: Retrieval improvement and validation against TCCON measurements. J. Geophys. Res. Atmos. 2020, 125, e2020JD032794. [CrossRef]

23. Butz, A.; Guerlet, S.; Hasekamp, O.; Schepers, D.; Galli, A.; Aben, I.; Frankenberg, C.; Hartmann, J.-M.; Tran, H.; Kuze, A.; et al. Toward accurate $\mathrm{CO}_{2}$ and $\mathrm{CH}_{4}$ observations from GOSAT. Geophys. Res. Lett. 2011, 38, 130-137. [CrossRef]

24. Zhou, M.Q.; Zhang, X.Y.; Wang, P.C.; Wang, S.P.; Guo, L.L.; Hu, L.Q. XCO 2 satellite retrieval experiments in short-wave infrared spectrum and ground-based validation. Sci. China Earth Sci. 2015, 58, 1191-1197. [CrossRef]

25. Wunch, D.; Toon, G.C.; Blavier, J.F.L.; Washenfelder, R.A.; Notholt, J.; Connor, B.J.; Griffith, D.W.T.; Sherlock, V.; Wennberg, P.O. The Total Carbon Column Observing Network (TCCON). Philos. Trans. R. Soc. A 2011, 369, 2087-2112. [CrossRef] [PubMed]

26. Wennberg, P.O.; Roehl, C.; Wunch, D.; Toon, G.C.; Blavier, J.-F.; Washenfelder, R.; Keppel-Aleks, G.; Allen, N.; Ayers, J. TCCON data from Park Falls, Wisconsin, USA, Release GGG2014R1; TCCON data archive, hosted by CaltechDATA; California Institute of Technology: Pasadena, CA, USA, 2017.

27. Griffith, D.W.T.; Velazco, V.A.; Deutscher, N.; Murphy, C.; Jones, N.; Wilson, S.; Macatangay, R.; Kettlewell, G.; Buchholz, R.R.; Riggenbach, M. TCCON data from Wollongong, Australia, Release GGG2014R0; TCCON data archive, hosted by CaltechDATA; California Institute of Technology: Pasadena, CA, USA, 2017. [CrossRef]

28. Kuze, A.; Suto, H.; Shiomi, K.; Kawakami, S.; Tanaka, M.; Ueda, Y.; Deguchi, A.; Yoshida, J.; Yamamoto, Y.; Kataoka, F.; et al. Update on GOSAT TANSO-FTS performance, operations, and data products after more than 6 years in space. Atmos. Meas. Tech. 2016, 9, 2445-2461. [CrossRef]

29. Rozanov, A.; Rozanov, V.; Buchwitz, M.; Kokhanovsky, A.; Burrows, J.P. SCIATRAN 2.0—A new radiative transfer model for geophysical applications in the 175-2400 nm spectral region. Adv. Space Res. 2005, 36, 1015-1019. [CrossRef] 
30. Rozanov, V.V.; Rozanov, A.V.; Kokhanovsky, A.A.; Burrows, J.P. Radiative transfer through terrestrial atmosphere and ocean: Software package SCIATRAN. J Quan. Spectrosc. Radiat. Transf. 2014, 133, 13-71. [CrossRef]

31. Guerlet, S.; Butz, A.; Schepers, D.; Basu, S.; Hasekamp, O.P.; Kuze, A.; Yokota, T.; Blavier, J.-F.; Deutscher, N.M.; Griffith, D.W.; et al. Impact of aerosol and thin cirrus on retrieving and validating $\mathrm{XCO}_{2}$ from GOSAT shortwave infrared measurements. $J$. Geophys. Res. Atmos. 2013, 118, 4887-4905. [CrossRef]

32. Oshchepkov, S.; Bril, A.; Yokota, T. PPDF-based method to account for atmospheric light scattering in observations of carbon dioxide from space. J. Geophys. Res. 2008, 113, D23210. [CrossRef]

33. Sanghavi, S.; Nelson, R.; Frankenberg, C.; Gunson, M. Aerosols in oco-2/gosat retrievals of $x \mathrm{CO}_{2}$ : An information content and error analysis. Remote Sens. Environ. 2020, 251, 112053. [CrossRef]

34. Pougatchev, N.; August, T.; Calbet, X.; Hultberg, T.; Oduleye, O.; Schlüssel, P.; Stiller, B.; Germain, K.S.; Bingham, G. IASI temperature and water vapor retrievals error assessment and validation. Atmos. Chem. Phys. 2009, 9, 6453-6458. [CrossRef]

35. Chen, X.; Liu, Y.; Yang, D.; Cai, Z.; Wang, M. A Theoretical Analysis for Improving Aerosol-Induced $\mathrm{CO}_{2}$ Retrieval Uncertainties Over Land Based on TanSat Nadir Observations Under Clear Sky Conditions. Remote Sens. 2019, 11, 1061. [CrossRef]

36. Noël, S.; Reuter, M.; Buchwitz, M.; Borchardt, J.; Warneke, T. XCO 2 retrieval for GOSAT and GOSAT-2 based on the FOCAL algorithm. Atmos. Meas. Tech. 2020, 14, 3837-3869. [CrossRef]

37. Aben, I.; Hasekamp, O.; Hartmann, W. Uncertainties in the space-based measurements of $\mathrm{CO}_{2}$ columns due to scattering in the Earth's atmosphere. J. Quant. Spectrosc. Radiat. Transf. 2007, 104, 450-459. [CrossRef]

38. Butz, A.; Hasekamp, O.P.; Frankenberg, C.; Aben, I. Retrievals of atmospheric $\mathrm{CO}_{2}$ from simulated spaceborne measurements of backscattered near-infrared sunlight: Accounting for aerosol effects. Appl. Opt. 2009, 48, 3322. [CrossRef] [PubMed]

39. Ye, H.H.; Wang, X.H.; Wu, J.; Fang, Y.H.; Ma, J.J.; Jiang, X.H.; Wei, Q.Y. Study of the effect of surface reflectance on atmospheric $\mathrm{CO}_{2}$ retrieval and ratio spectrometry. Spectrosc. Spect. Anal. 2013, 33, 2182-2187.

40. Connor, B.; Bösch, H.; McDuffie, J.; Taylor, T.; Fu, D.; Frankenberg, C.; O’Dell, C.; Payne, V.H.; Gunson, M.; Pollock, R.; et al. Quantification of uncertainties in OCO-2 measurements of $\mathrm{XCO}_{2}$ : Simulations and linear error analysis. Atmos. Meas. Tech. 2016, 9, 5227. [CrossRef]

41. Kiel, M.; O'Dell, C.W.; Fisher, B.; Eldering, A.; Wennberg, P.O. How bias correction goes wrong: Measurement of XCO2 affected by erroneous surface pressure estimates. Atmos. Meas. Tech. 2019, 12, 2241-2259. [CrossRef]

42. Rusli, S.P.; Hasekamp, O.; Brugh, J.; Fu, G.; Landgraf, J.C. Anthropogenic $\mathrm{CO}_{2}$ monitoring satellite mission: The need for multi-angle polarimetric observations. Atmos. Meas. Tech. 2021, 14, 1167-1190. [CrossRef] 